\title{
Effects of Communicable Diseases on Life Expectancy in Low- and Lower-Middle-Income Countries
}

\author{
SHARIFUL ISLAM ${ }^{1}$; NAZRUL ISLAM MONDAL 2 , REJAUL KARIMํ, MOHAMMAD ROCKY KHAN CHOWDHURY4 ${ }^{4}$, AMINUR \\ RAHMAN ${ }^{5}$, HAFIZ T.A. KHAN ${ }^{6}$ \\ ${ }^{1}$ Lecturer, Department of Public Health, First Capital University of Bangladesh, Chuadanga, Chuadanga-7200, Bangladesh \\ ${ }^{2}$ Professor, Department of Population Science and Human Resource Development, University of Rajshahi, Rajshahi-6205, Bangladesh \\ ${ }^{3}$ Assistant Professor, Department of Pediatrics, Rajshahi Medical College, Rajshahi 6100; Bangladesh \\ ${ }^{4}$ Research Fellow, Department of Population Science and Human Resource Development, University of Rajshahi, Bangladesh \\ ${ }^{5}$ Assistant Professor, Department of Population Science and Human Resource Development, University of Rajshahi, Bangladesh \\ ${ }^{6}$ Professor of Public Health \& Statistics, The Graduate School, University of West London, St Mary's Road, London W5 5RF; UK \\ Correspondence to Professor Dr. Md. Nazrul Islam Mondal, E-mail: nazrulupm@gmail.com, Phone: +8801716922856
}

\begin{abstract}
Background: Life expectancy (LE) at birth is relatively poor in thelow- and lower-middle-income countries compared to the developed countries. There are many factors for this poor status of LE in these countries. Communicable disease in the human body is found to be one of the main causes.

Aim: To determine the effects of communicable diseases on LE at birth in low- and lower-middle-income countries.

Methods: Data of 82 low- and lower-middle-income countries were extracted from the World Health Statistics 2018. In this study, the dependent variable is LE at birth, and the communicable diseases such as new Human Immunodeficiency (HIV) infections, Tuberculosis (TB) incidences, Malaria incidences, and Hepatitis-B surface antigen $(\mathrm{HBsAg})$ prevalence among children under 5 years are the independent variables. Descriptive statistics, Pearson's correlation analysis, and Linear regression model were used to examine the data.

Results: The lowest (52.90 years) and highest (76.30 years) LE at birth were observed in Lesotho and Viet Nam, respectively. Pearson's correlation coefficients identified that new HIV infections, TB incidences, Malaria incidences, and HBsAg prevalence among children under 5 years are highly correlated with the LE at birth. The linear regression analysis reveals that all the selected variables are found to have significant negative effects on LE at birth in low and lowermiddleincome countries.

Conclusions: The higher prevalence of communicable diseases contributes to reducing the LE at birth in low and lowermiddleincome countries. So, to raise the LE at birth of a country, the necessary steps should be taken to minimize the incidence and prevalence of communicable diseases.
\end{abstract}

Keywords: Life expectancy; Communicable diseases;Low- and lower-middle-income countries

\section{INTRODUCTION}

Life expectancy (LE) is a statistical measure of the average time whicha human being is expected to live at a certain age. It is a hypothetical measure of a country and is widely used for measuring the overall development. The LE is the mean number of years of life remaining at a given age ${ }^{1}$. LEs at birth are relatively low in the low and lowermiddleincome countries than developed countries. Despite the sharp increase of LEat birth from 65.50 years in 2000 to 72.00 years in 2016 in low-income countries, LE in highincome countries is still high ${ }^{2}$. Several factors are responsible for poor LE status for a country which includes social factors, demographic factors, economic factors and, clinical factors ${ }^{3-9}$. Infectious diseases, such as Malaria, Human Immunodeficiency (HIV) infections, Tuberculosis (TB), Hepatitis B surface antigen (HBsAg), Measles, Mumps, Ebola, Zika, Nipah, Poliovirus,Rickettsia in the human body are the root cause of poor LE status ${ }^{10-12}$. Infectious diseases can be defined as any diseases that can be occurred by bacteria, viruses, parasites or fungi. Infectious disease is often termed as the communicable disease because of smooth communication ability of these pathogens from one individual to another. The most common communicable diseases are Malaria, HIV infections, TB and $\mathrm{HBsAg}^{2}$.
A few numbers of studies have been carried out around the world that identified hypopituitarism, intellectual disability, physical inactivity, etc. were the risk factors of LE $^{13-16}$. Boutayeb (2006) has reviewed some literature of developing countries, related to communicable and noncommunicable diseases and revealed a universal view of these diseases and their effect on populations living in lowand middle-income nations ${ }^{11}$. Marais et al. (2013)demonstrated that tuberculosis and HIV/AIDS have been considered as global crises that are responsible for a high mortality rate. They also claimed that in sub-Saharan Africa, there is a deadly interaction between tuberculosis and HIV infection among the adults, children, and pregnant women which demandedthe well-integrated approaches for controlling thesituation ${ }^{17}$. The emerging levels of major factors influencing the LE are the chronic diseases and accidental injuries ${ }^{18}$. The inhabitants of low-income countries still suffer an enormous burden of disease owing to diarrhea, pneumonia, HIV/AIDS, tuberculosis, malaria and other pathogens ${ }^{19}$. Research on LE has been carried all around the world but none of it has examined the effects of communicable diseases on LE at birth in low and lowermiddleincome countries in past decades. Theaimof this present study is to determine the effects of communicable diseases on LE at birth in low and lowermiddleincome countries. 


\section{METHODOLOGY}

Data of 82 low and lowermiddleincome countries were extracted from the World Health Statistics 2018. The dependent variable,Life Expectancy (LE) at birth measures the quantity of life a person expects to live ${ }^{1}$. On the other hand, communicable diseases like-new Human Immunodeficiency (HIV) infections, Tuberculosis (TB) incidences, Malaria incidences, and Hepatitis B surface antigen (HBsAg) prevalence among children under 5 years were considered as the independent variables (Appendix A).

Descriptive measurements were used to enunciate the overall situations of our study variables in low and lowermiddleincome countries. Pearson's correlation analysis was executed to explore the relationships among the study variables. Before examining the effects of communicable diseases on LE at birth, the multicollinearity problem were checked by using the tolerance values. If the tolerance value is less than 0.40 then it is assumed thatthere is a strong multicollinearity ${ }^{1}$, and there is no multicollinearity among the independent variables of this study. And finally, a linear regression analysis was performed to identify the effects of communicable diseases on the LE at birth in this study.

The whole analysis of this study is completed with the statistical software Stata/MP version 13.1 and SPSS to reach our objectives. Microsoft Excel and Statistical Package Program $\mathrm{R}$ are also used to complete this study. Additionally, the reference is added by using the software named 'EndNote X7.4 (Bld 8818)' in this study.

\section{RESULTS}

Table 1 shows the descriptive statistics of the study variables in 82 low- and lowermiddle-income countries (see Fig. 1). The LE at birth is observed very low among SubSaharan African countries, and very high among the East Asia and Pacific countries, and Middle East and North African countries. But all the communicable diseases, considered in this study are high among Sub-Saharan
African countries. On the other hand, the lowest HIV infections, TB incidence, Malaria incidence, and HBsAg have observed among the South Asian and Middle East and North African countries; the Middle East and North African countries; Europe and Central Asian countries; Latin America and Caribbean countries, respectively.

The lowest (52.90 years) and highest (76.30 years) LE at birth were observed in Lesotho and Viet Nam, respectively. Both the new HIV infections (12.68) and TB incidence (724.00) are highest in Lesotho. On the other hand, the lowest scenarios of new HIV infections (0.01) are seen in Bangladesh, Comoros, Jordan, and Mongolia. But the lowest TB incidence (5.60) is seen in Jordan. Again the Malaria incidence is high (459.70) in Mali, and low (0.00) in Georgia, Kyrgyzstan, Sri Lanka, Tajikistan, and Uzbekistan. Among the low and lowermiddleincome countries, the highest (21.13) HBsAg prevalence among children under 5 years is found in South Sudan, and the lowest (0.05) HBsAg is found in Guatemala.

Table 2 shows the Pearson's correlation coefficients which identified the significant negative relationships of LE at birth with new HIV infections $(r=-0.42, p<0.01)$, TB incidences $(r=-0.35, p<0.01)$, Malaria incidences $(r=-$ $0.66, p<0.01)$, and HBsAg $(r=-0.51, p<0.01)$ in the low and lowermiddleincome countries of the world.

Table 3 symbolizes the outcomes of a simple linear regression model. The regression analysis identified the communicable diseases, like- new HIV infection, TB incidences, Malaria incidences, and HBsAg prevalence among children under 5 years are the affecting factors of LE at birth in the low and lowermiddle-income countries. Among all these communicable diseases the new HIV infections, Malaria incidences, and HBsAgprevalence among children under 5 years have shown negative significant effects on LE at birth. Hence among all the independent variables, the higher rate of new HIV infections, Malaria incidences, and HBsAgprevalence among children under 5 years are the most affecting factors in low and lowermiddle- income countries which decrease the nation's average LE at birth.

Table 1: Descriptive statistics of the selected variables for the low-income and lower-middle-income countries

\begin{tabular}{|c|c|c|c|c|c|c|c|c|c|}
\hline \multirow{2}{*}{ Variables } & \multirow{2}{*}{$N$} & \multirow{2}{*}{ Mean \pm SE } & \multirow{2}{*}{ Median } & \multirow{2}{*}{ SD } & \multirow{2}{*}{ Variance } & \multicolumn{2}{|c|}{ Minimum } & \multicolumn{2}{|c|}{ Maximum } \\
\hline & & & & & & Value & Country & Value & Country \\
\hline Y & 82 & $65.88 \pm 0.68$ & 65.85 & 6.18 & 38.24 & 52.90 & Lesotho & 76.30 & Viet Nam \\
\hline $\mathrm{X}_{1}$ & 72 & $0.86 \pm 0.23$ & 0.21 & 1.93 & 3.72 & 0.01 & Bangladesh, Comoros, Jordan, and Mongolia & 12.68 & Lesotho \\
\hline $\mathrm{X}_{2}$ & 82 & $199.32 \pm 17.04$ & 157.50 & 154.27 & 23799.15 & 5.60 & Jordan & 724.00 & Lesotho \\
\hline $\mathrm{X}_{3}$ & 70 & $115.86 \pm 16.22$ & 51.05 & 135.73 & 18422.51 & 0.00 & $\begin{array}{l}\text { Georgia, Kyrgyzstan, Sri Lanka, Tajikistan, and } \\
\text { Uzbekistan }\end{array}$ & 459.70 & Mali \\
\hline $\mathrm{X}_{4}$ & 82 & $2.57 \pm 0.33$ & 1.73 & 3.02 & 9.12 & 0.05 & Guatemala & 21.13 & South Sudan \\
\hline
\end{tabular}

Notes: 'N, number of countries', 'SE, standard error', 'SD, standard deviation', ' $\mathrm{Y}$, life expectancy at birth', ' $\mathrm{X}_{1}$, human immunodeficiency virus infections', ' $\mathrm{X}_{2}$, tuberculosis incidence', ' $X_{3}$, malaria incidence', ' $X_{4}$, hepatitis $B$ surface antigen'

Table 2: Pearson correlation coefficients between variables
\begin{tabular}{|l|c|c|c|c|c|}
\hline & $\mathbf{Y}$ & $\mathbf{X}_{\mathbf{1}}$ & $\mathbf{X}_{\mathbf{2}}$ & $\mathbf{X}_{\mathbf{3}}$ & $\mathbf{X}_{\mathbf{4}}$ \\
\hline Life expectancy at birth $(\mathbf{Y})$ & 1 & & & & \\
\hline Human Immunodeficiency Virus infections $\left(\mathbf{X}_{\mathbf{1}}\right)$ & $-0.42^{* *}$ & 1 & & & \\
\hline Tuberculosis incidence $\left(\mathbf{X}_{\mathbf{2}}\right)$ & $-0.35^{* *}$ & $0.58^{* *}$ & 1 & & \\
\hline Malaria incidence $\left(\mathbf{X}_{\mathbf{3}}\right)$ & $-0.66^{* *}$ & 0.13 & -0.02 & 1 & \\
\hline Hepatitis B surface antigen $\left(\mathbf{X}_{\mathbf{4}}\right)$ & $-0.51^{* *}$ & 0.04 & 0.06 & $0.41^{* *}$ & 1 \\
\hline
\end{tabular}

Notes: “**, $p<0.01$ ' 
Table 3: Linear regression model explaining the life expectancy in low-income and lower-middle-income countries

\begin{tabular}{|c|c|c|c|c|c|}
\hline \multirow{2}{*}{ Explanatory Variables } & \multirow{2}{*}{$\begin{array}{l}\text { Regression } \\
\text { coefficient, } \beta\end{array}$} & \multirow{2}{*}{ SE of $\beta$} & \multicolumn{2}{|c|}{$95 \% \mathrm{Cl}$ of $\beta$} & \multirow{2}{*}{$P$ value } \\
\hline & & & Minimum & Maximum & \\
\hline Human Immunodeficiency Virus infections $\left(\mathbf{X}_{1}\right)$ & -0.84 & 0.393 & -1.627 & -0.052 & 0.04 \\
\hline Tuberculosis incidence' $\left(\mathbf{X}_{2}\right)$ & -0.01 & 0.004 & -0.015 & 0.001 & 0.09 \\
\hline Malaria incidence $\left(\mathbf{X}_{3}\right)$ & -0.02 & 0.004 & -0.029 & -0.013 & 0.00 \\
\hline Hepatitis B surface antigen $\left(\mathbf{X}_{4}\right)$ & -0.58 & 0.169 & -0.921 & -0.245 & 0.00 \\
\hline$R_{a}^{2}$ & \multicolumn{5}{|c|}{0.57} \\
\hline
\end{tabular}

Notes: 'SE, standard error'; 'Cl, confidence interval'

Fig. 1: Overall situation of the study variables in low- and lower-middle-income countries
LE
HIV
TB
ML
HB
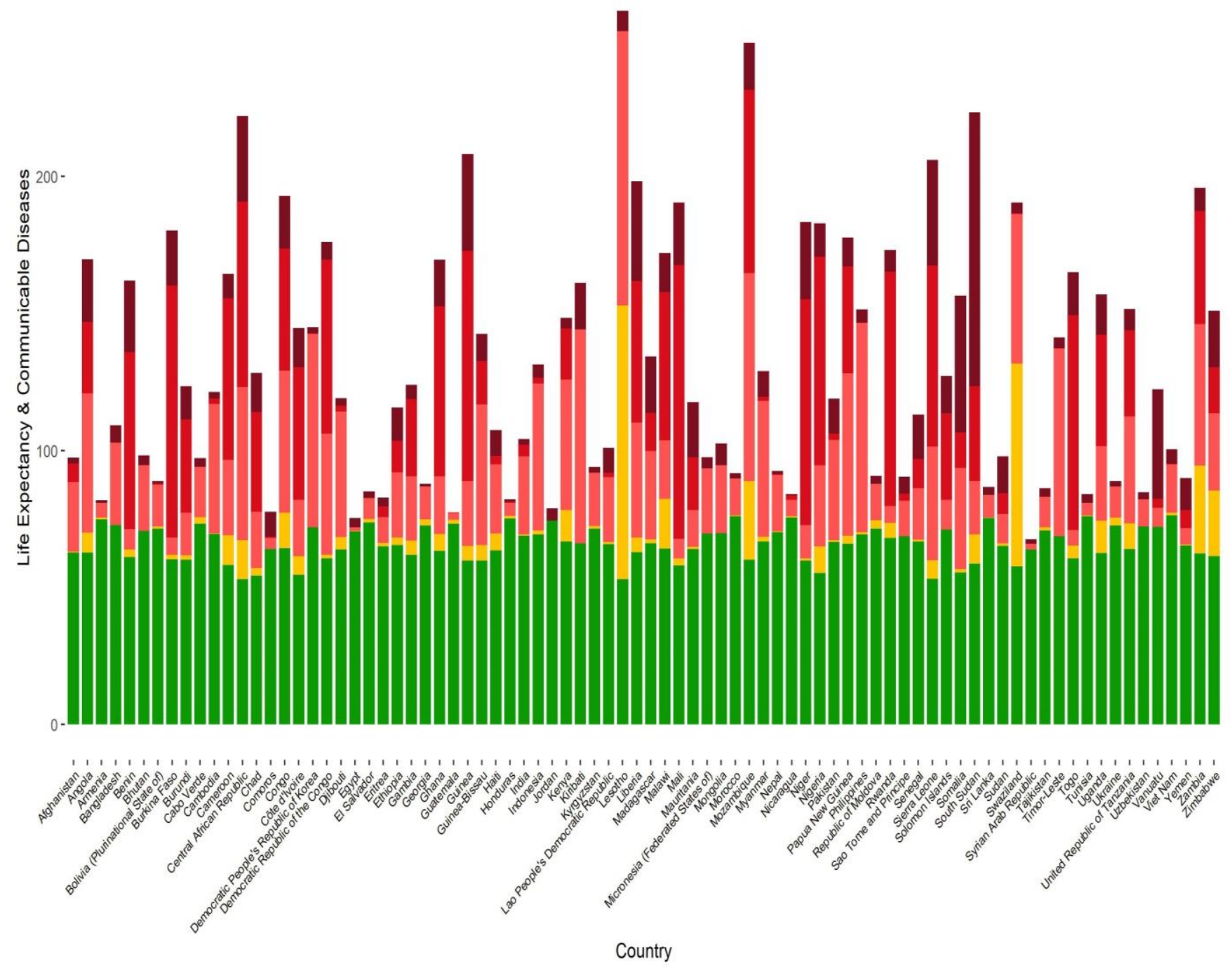
Fig.2 Life Expectancy at birth (in years) in lowest ten countries

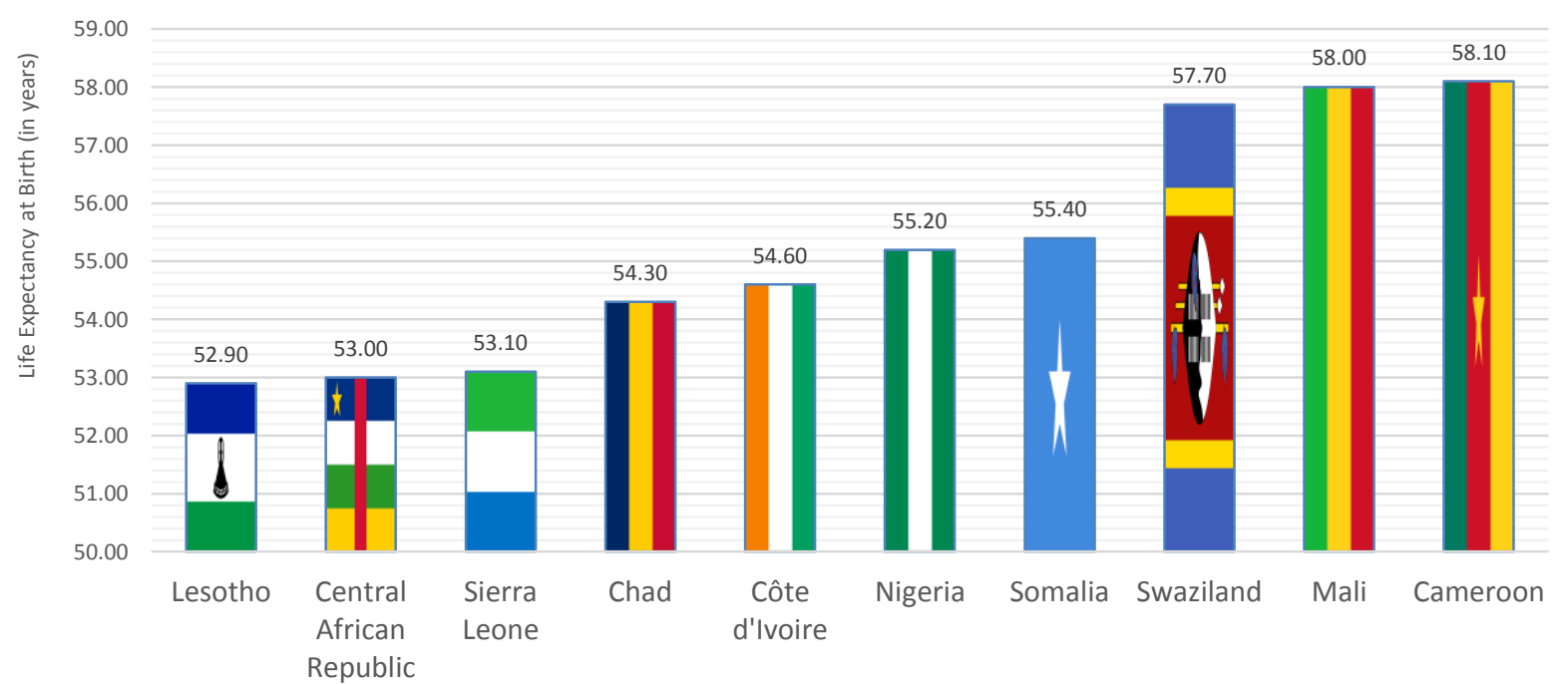

Most Lowest 10 Countries

\section{DISCUSSION}

A commonly applied and analyzed component of overall health and demographic data for any country is the LE at birth. The main objective of this research is to express the effects of communicable diseases on LE at birth in low and lowermiddleincome countries. Among the communicable diseases the new HIV infections, Malaria incidences, and HBsAg prevalence among children under 5 years are found as the most influential factors of LE at birth in this study. In many developing countries, especially in Africa, new HIV infection is one of the most dangerous public health and developmental threats ${ }^{20}$. People living with HIV face the rapid loss of immunity and, 9-11 years living without treating the infection results shortness of lifespan ${ }^{21}$. High HIV prevalence in a country is responsible for decrease average $L^{22}$.

Additionally, a new HIV infection (per 1000 uninfected population) is an important causal factor of LE at birth. According to our source, low LE at birth(see Fig. 2) has been identified for most countries and new HIV infections are high among Sub-Saharan African countries. In 2017, the World Health Organization (WHO) reported that approximately 36.90 million individuals were living with HIV and 1.80 million individuals becoming newly infested globally ${ }^{23}$. Among that 25.70 million people were living in the WHO African Region which is the maximum affected region in the world. In the case of new HIV infections,more than two-thirds of new HIV infected people in the world live in African region ${ }^{23}$. If the present trend persists, AIDS will be responsible for too many deaths than any other diseases by 2020 in the world's history ${ }^{24}$. Therefore this study revealed thatthe higher rate of new HIV infection is one of the most important causes of lower LE at birth. In this study, LE at birth decreases due to an increase in new HIV infection. But if an HIV infected person is able to identify it in proper time, garb the opportunity of good lifelong observance and variety of current drugs, s/he can expect to have a higher LE at birth ${ }^{25}$.

Another influential factor of a country's average LE at birth is malaria incidences (per 1000 population at risk). Also, it has negative effects on LE at birth in the low and lowermiddle-income countries. Although the success rate of several vaccination programs is impressive, the situation of malaria incidence is still very high in many developing countries ${ }^{11}$. According to the WHO, more than one million people are identified as malaria infected each year ${ }^{26}$. Children, pregnant women, and older people are found most vulnerable to this cause ${ }^{26}$. In Sub-Saharan African countries malaria caused more than $90.00 \%$ of deaths each year ${ }^{27}$. Malaria incidence is high (459.70 per 1000) in Mali, a Sub-Saharan African country. Most of the malaria deaths in 2016 were reported in the WHO African Region, whereas it was only $6.00 \%$ in the WHO South-East Asian Region $^{28}$. The death rate in the African region is increasing each year ${ }^{26}$. It was reported that globally 435000 deaths were occurred due to malaria, compared with 451,000 deaths estimated in 2016, and 607,000 in 201026. Since the LE at birth is very low and malaria incidences are high among the Sub-Saharan African countries, hence it is needed to control the malaria incidences in these regions to increase the LE at birth.

Liver disease due to Hepatitis B surface antigen (HBsAg) prevalence among children under 5 years ${ }^{29}$ is one of the adverse communicable diseases in low and lowermiddle-income countries. It is one of the significant causes of lower average LE at birth in the study areas. According to the findings of regression analysis, $\mathrm{HBsAg}$ prevalence among children under 5 years had significant negative effects on LE at birth in low and lowermiddleincome countries. LE at birth decreases throughout the Sub-Saharan African countries at an alarming rate due to the increase in $\mathrm{HBsAg}$ prevalence among children under 5 years ${ }^{30}$. Another study said that 
the increasing HBsAg prevalence among children under 5 years is an influential factor in narrowing the $L^{31}$.

This study, like others, has a limitation which is that we only consider a few communicable diseases categorized by WHO. Also, the mortality-related factors are not considered in this studywhich will be our next research field. But, the strong point of this study is that the data source is a most reliable.

\section{CONCLUSION}

This study identified that all the variables under study have highly negative significant impacts on LE at birth in low and lowermiddleincome countries. To increase the level of LE at birth in these countries, minimizing incidences of new HIV infections, TB incidence, Malaria incidence, and HBsAg prevalence among children under 5 years are demanded. Therefore we may conclude by saying that as the higher prevalence of communicable diseases contributes to reducing the LE at birth, it is needed to raise the LE at birth of a country by taking necessary steps to minimize the prevalence of communicable diseases in low and lowermiddleincome countries.

\section{REFERENCE}

1. Islam MS, Tareque MI, Mondal MNI, Rabbi AMF, Khan HT, et.al. Urban-rural differences in disability-free life expectancy in Bangladesh using the 2010 HIES data. PloS one, 2017;12(7):e0179987.

2. WHO. World health statistics 2018: monitoring health for the SDGs, sustainable development goals. World Health Organization (WHO), Switzerland, Geneva; 2018.

3. Senterfitt JW, Long A, Shih M, Teutsch SM. How social and economic factors affect health: Los Angeles County of Department of Public Health; 2013.

4. Jensen TK, Jacobsen R, Christensen $K$, Nielsen NC, Bostofte E. Good semen quality and life expectancy: a cohort study of 43,277 men. American journal of epidemiology, 2009;170(5):559-565.

5. Körsgen $S$, Keighley $M$. Causes of failure and life expectancy of the ileoanal pouch. International journal of colorectal disease, 1997;12(1):4-8.

6. Wilson M, Daly M. Life expectancy, economic inequality, homicide, and reproductive timing in Chicago neighbourhoods. BMJ, 1997;314(7089):1271.

7. Barwick $\mathrm{H}$, Nuthall JJ. The Impact of Economic and Social Factors on Health.The Public Health Association, Department of Health, 1992; New Zealand.

8. Mondal M, Shitan M. Impact of socio-health factors on life expectancy in the low- and lower-middle-income countries. Iranian journal of public health, 2013;42(12):1354.

9. Mondal MNI, Ullah MMMN, Islam MR, Rahman MS, Khan $\mathrm{MN}$, et. al. Sociodemographic and Health Determinants of Inequalities in Life Expectancy in Least Developed Countries.International Journal of $\mathrm{MCH}$ and AIDS, 2015,4(1):1-10.

10. Anderson RM, May RM. Infectious diseases of humans: dynamics and control: Oxford university press; 1992.

11. Boutayeb A. The double burden of communicable and noncommunicable diseases in developing countries. Transactions of the Royal society of Tropical Medicine and Hygiene, 2006;100(3):191-199.
12. Mondal M, Shitan M. Factors affecting the HIV/AIDS epidemic: an ecological analysis of global data. African health sciences, 2013;13(2):301-310.

13. Bates A, Van't Hoff W, Jones P, Clayton R. The effect of hypopituitarism on life expectancy. The Journal of Clinical Endocrinology \& Metabolism, 1996;81(3):1169-72.

14. Bittles AH, Petterson BA, Sullivan SG, Hussain R, Glasson EJ, et. al. The influence of intellectual disability on life expectancy. The Journals of Gerontology Series $A$ : Biological Sciences and Medical Sciences, 2002;57(7):47072 .

15. Lee IM, Shiroma EJ, Lobelo F, et. al. Effect of physical inactivity on major non-communicable diseases worldwide: an analysis of burden of disease and life expectancy. The Lancet, 2012;380(9838):219-229.

16. Murdoch JL, Walker BA, Halpern BL, Kuzma JW, McKusick VA. Life expectancy and causes of death in the Marfan syndrome. New England Journal of Medicine, 1972;286(15):804-808.

17. Marais BJ, Loennroth K, Lawn SD, et al. Tuberculosis comorbidity with communicable and non-communicable diseases: integrating health services and control efforts. The Lancet infectious diseases, 2013;13(5):436-448.

18. Liu P, Li, C., Wang, Y., Zeng, W., Wang, H., Wu, H., ... \& Hao, M. The impact of the major causes of death on life expectancy in China: a 60-year longitudinal study BMC public health, 2014;14(1):1193.

19. Dye C. After 2015: infectious diseases in a new era of health and development. PhilosophicalTransactions of the Royal Society B: Biological Sciences, 2014;369(1645):20130426.

20. Karim SSA, Churchyard GJ, Karim QA, Lawn SD. HIV infection and tuberculosis in South Africa: an urgent need to escalate the public health response. The Lancet, 2009;374(9693):921-933.

21. Brandon E, Morris ML. Global trends influencing CIMMYT's future: Cimmyt; 2003.

22. Mondal MNI, Shitan M. Relative importance of demographic, socioeconomic and health factors on life expectancy in lowand lower-middle-income countries. Journal of Epidemiology, 2014;24(2):117-124.

23. Hernandez J, Kumar A. Globalized Means for Diagnostic and Preventative Management of HIV/AIDS. International STD Research \& Reviews, 2018:1-5.

24. Mathers CD, Loncar D. Projections of global mortality and burden of disease from 2002 to 2030. PLoS medicine, 2006;3(11):e442.

25. Nakagawa $F$, May M, Phillips A. Life expectancy living with HIV: recent estimates and future implications. Current opinion in infectious diseases, 2013;26(1):17-25.

26. WHO. World Malaria Report 2018. World Health Organization (WHO) 2018,Switzerland, Geneva.

27. Ruxin J, Paluzzi JE, Wilson PA, Kruk M, Teklehaimanot A. Emerging consensus in HIV/AIDS, malaria, tuberculosis, and access to essential medicines. The Lancet, 2005;365(9459):618-621.

28. WHO. World Malaria Report 2017:World Health Organization (WHO) 2017,Switzerland, Geneva.

29. Beasley R. Overview on the epidemiology of hepatocellular carcinoma. Viral Hepatitis and Liver Diseases, 1991.

30. Breakwell L, Tevi-Benissan C, Childs L, Mihigo R, Tohme R. The status of hepatitis $\mathrm{B}$ control in the African region. The Pan African medical journal, 2017;27(Suppl 3).

31. Ott J, Stevens G, Groeger J, Wiersma S. Global epidemiology of hepatitis $B$ virus infection: new estimates of age-specific HBsAg seroprevalence and endemicity. Vaccine, 2012;30(12):2212-2219. 